\title{
Measurement of pressure loss coefficient for nuclear fuel assembly
}

\author{
Pavel Nerud ${ }^{1 *}$ \\ ${ }^{1}$ Škoda JS a.s., Orlík 266, Plzeň, 316 00, Czech Republic
}

\begin{abstract}
Design and operation of nuclear reactor is very difficult issue from the engineering and technical point of view. All facilities must be availably designed separately, but with respect to other facilities working in the same system too. In nuclear power plant the key safety factor is the insurance of nuclear fuel assemblies cooling. The basic requirement from this point of view is an pressure loss coefficient assessment for all possible modes of coolant flow. This article describes an experience with measurement of pressure loss coefficient characteristics in Škoda JS.
\end{abstract}

\section{Introduction}

The one of basic safety requirements in process of design and operation of nuclear reactor is insurance of nuclear fuel assembly cooling in all possible conditions, it means during reactor operation, during pool storage and transport in container. The sufficient cooling of the fuel assembly and all its parts is possible only, when these parts have right coefficient of pressure loss coefficient and at the same time right distribution of this coefficient between parts in fuel assembly is preserved.

\section{Nuclear fuel assembly}

Nuclear fuel assembly for VVER reactors (PWR eventually) contains:

- bundle of fuel pins,

- top nozzle and bottom nozzle (provide right position and attachment due to other reactor internals),

- $\quad$ structural grids (keep right distance between fuel pins),

- $\quad$ supporting parts getting mechanical rigidity of fuel assembly (in some types),

- guide tubes for absorber cluster (in fuel assembly for reactor VVER 1000 and PWR),

- $\quad$ outer shroud (in fuel assembly for reactor VVER 440 only).

In Fig. 1 a structure of upper part of fuel assembly for VVER 440 is shown. In this cut it is possible to see top nozzle and safety grid, which protects heads of fuel pins against foreign objects fall. Six plugs in upper parts of the top nozzle are pushed away by spring. Their

* Corresponding author: Pavel.Nerud@skoda-js.cz 
function is to compensate forces produced by upper reactor internals in movement to right position in reactor and during operation. Under safety grid, there is hexagonal structural grid, which keeps fuel pins in right position and enables sufficient coolant flow. An outer shroud is protecting fuel bundle against damage and acts like flow channel for coolant. Every part has its own pressure loss coefficient, which acts against coolant flow around nuclear fuel pins. In process of shape, material and surface design it is needed to take into account this coefficient and confirm this by real measurement for every flow regimes.

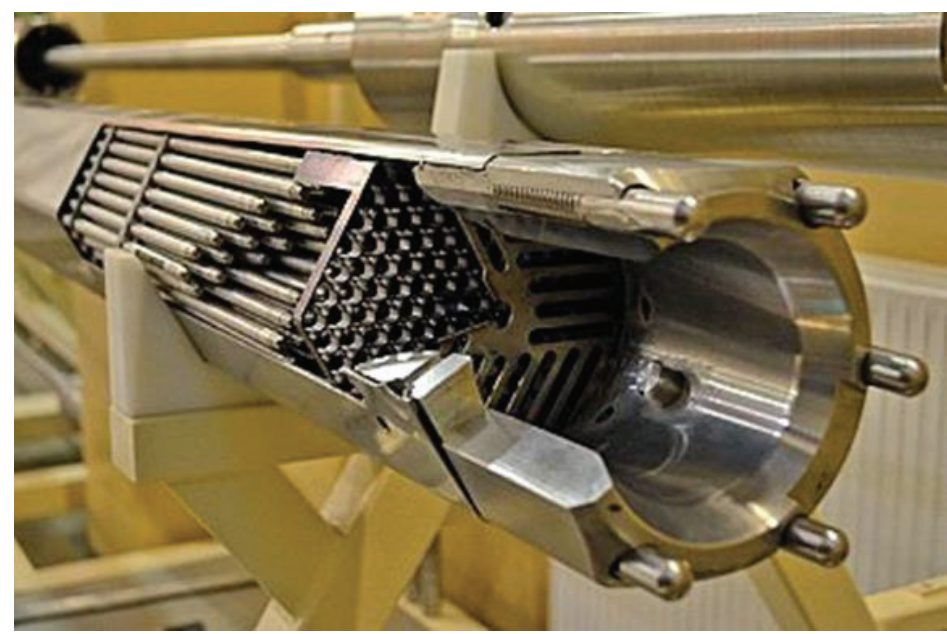

Fig. 1. A cut in top nozzle and bundle of fuel pins for VVER 440 fuel assembly [1]

\section{Experimental loop in Škoda JS}

Large water loop is experimental loop located in experimental hall in Škoda JS company. This loop is adapted for measurement for pressure loss coefficient, critical heat flux measurement on fuel pins surface and check of reliable operation for electrical drive of regulation cluster. Experimental loop contains experimental part for testing of mechanical behaviour during coolant flow; it is made by using special instrumented diagnostics fuel assembly. The next important part of experimental loop is so-called reflooding channel, where influence of hot fuel assembly reflooding after LOCA accident is tested.

This experimental loop allows pressure loss coefficient measurement for VVER 440 and VVER 1000 in two separated experimental channels. Its maximal operation parameters are written in Table 1.

Table 1. Parameters of experimental channels in Large Water Loop

\begin{tabular}{|l|c|c|}
\hline & VVER 440 & VVER 1000 \\
\hline Maximal operation pressure $[\mathrm{MPa}]$ & 12,5 & 15,7 \\
\hline Maximal operation temperature $\left[{ }^{\circ} \mathrm{C}\right]$ & 300 & 330 \\
\hline Maximal coolant flow $\left[\mathrm{m}^{3} / \mathrm{h}\right]$ & 180 & 600 \\
\hline Maximal temperature increase $\left[{ }^{\circ} \mathrm{C} / \mathrm{h}\right]$ & 120 & 60 \\
\hline Maximal electrical power $[\mathrm{kW}]$ & 155 & 120 \\
\hline
\end{tabular}


Experimental loop is equipped:

- temperature measurement in experimental channel inlet and outlet,

- $\quad$ static pressure measurement in experimental channel inlet and outlet,

- coolant flow measurement by Venturi nozzle in experimental channel inlet,

- $\quad$ pressure differences measurement between pressure taps in experimental channel.

Fig. 2 schematically shows differential pressure transducers locations in experimental channel. Some of pressure transducers are determined for direct measurement, other are determined for checksums of pressure differences. By this way the check of correctness is performed; exceptionally exclusion of incorrectly measuring pressure transducer from calculation.

The setting of right coolant flow is carried out by operator from hydraulic control room and in the next step is checked by independent measurement system.

$$
Q=\alpha_{V D} \cdot A_{V D} \cdot \sqrt{\frac{2000 \cdot d p_{V D}}{\rho}}
$$

In equation (1), $d p_{\mathrm{VD}}$ responses measured pressure difference in Venturi nozzle inlet and in its smallest diameter. Physical quantity $\alpha_{V D}$ is flow coefficient of Venturi nozzle, which is determined during calibration in certified laboratory. AvD is cross section of Venturi nozzle in the smallest diameter. Coolant density $\rho$ is determined during individual measurement as a function of measured temperature and pressure of coolant. Q is description for real flow rate.

It is needed to enumerate next values of physical quantities for gaining of pressure loss coefficient.

$$
R e_{F A}=\frac{Q \cdot d_{e F A}}{A_{F A} \cdot v}
$$

Equation (2) is enumeration of Reynolds number, which describes rate of coolant flow tubulisation in fuel assembly. This number is dependent on flow velocity, what is expressed by ratio of coolant flow rate $\mathrm{Q}$ and cross section area $\mathrm{A}_{\mathrm{FA}}$. Kinematic viscosity $v$ is property of coolant and characterizes its cohesiveness; it means a change of velocity on distance of adjacent layers during flow. Quantity $\mathrm{d}_{\mathrm{eFA}}$ is equivalent hydraulic diameter for bundle of fuel pins.

Enumeration of pressure loss coefficient generally can be expressed by equation

$$
\xi_{X Y}=\frac{\Delta p_{X Y}}{p_{d y n}}+\left(\frac{A_{X}}{A_{F A}}\right)^{2}-\left(\frac{A_{Y}}{A_{F A}}\right)^{2}-\lambda \cdot \frac{l_{X Y}}{d_{e F A}}
$$

Where

$$
p_{d y n}=\frac{\rho \cdot Q^{2}}{2 \cdot A_{F A}^{2}}
$$

Enumeration of coefficient $\xi$ for one structural grid number 3 (by Fig. 2) is written as a sample.

$$
\xi_{S G 3}=\frac{p_{H}-p_{L}}{p_{d y n}}-\lambda \cdot \frac{l_{L H}}{d_{e F A}}
$$


The first element in equation (5) is ratio of measured differential pressure between pressure taps $\mathrm{L}$ and $\mathrm{H}$ and enumerated dynamic pressure $\mathrm{p}_{\mathrm{dyn}}$ arising by coolant flow. Dynamic pressure is the same for all measured parts of fuel assembly. The second and the third element in equation (3) are used for correction of flow cross section area. These elements are not used in equation (5), because flow cross section is not changing between pressure taps $\mathrm{L}$ and $\mathrm{H}$. It is needed for using this correction for measurement on top or bottom nozzle of fuel assembly. Relative cross section area $A_{F A}$ under fraction line is equal to flow area in this case. The last element in equation (3) expresses influence of longitudinal friction on bundle of fuel pins. Quantity $1_{\mathrm{LH}}$ is distance between pressure taps $\mathrm{L}$ and $\mathrm{H}$ reduced by height of measured structural grid. Quantity $\lambda$ is longitudinal friction coefficient and it depends on flow regime and roughness of fuel pins roughness.

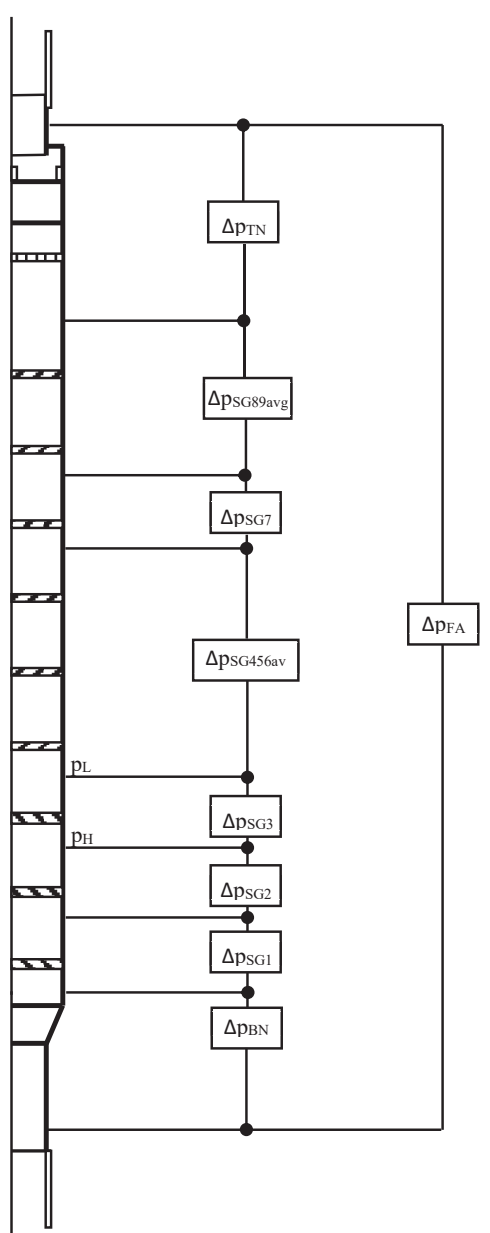

Fig. 2. Scheme of pressure differences measurement

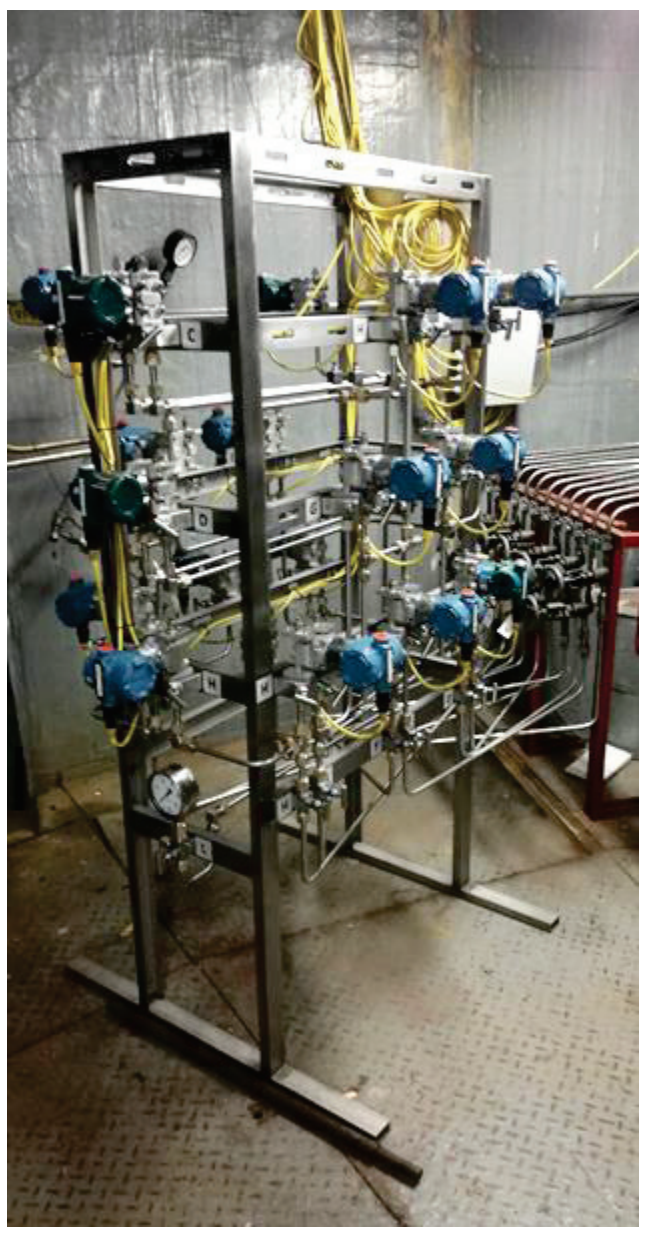

Fig. 3. Stand for measurement static pressure and pressure differences 
The result of pressure differences measurement and enumeration of pressure loss coefficients is graph, which describes development of pressure loss during change of flow velocity. This change is written by Reynolds number. Simulated sample of graph for measurement of structural grid, bundle of fuel pins and fuel assembly is given in Fig 4. In this graph appears cloud of points, which responses every single measured part. Because measured values have decreasing nonlinear character, the best interpolation is power curve. The distribution of measured points is not strictly on the line, it is caused by change of measuring error in every single measured point.

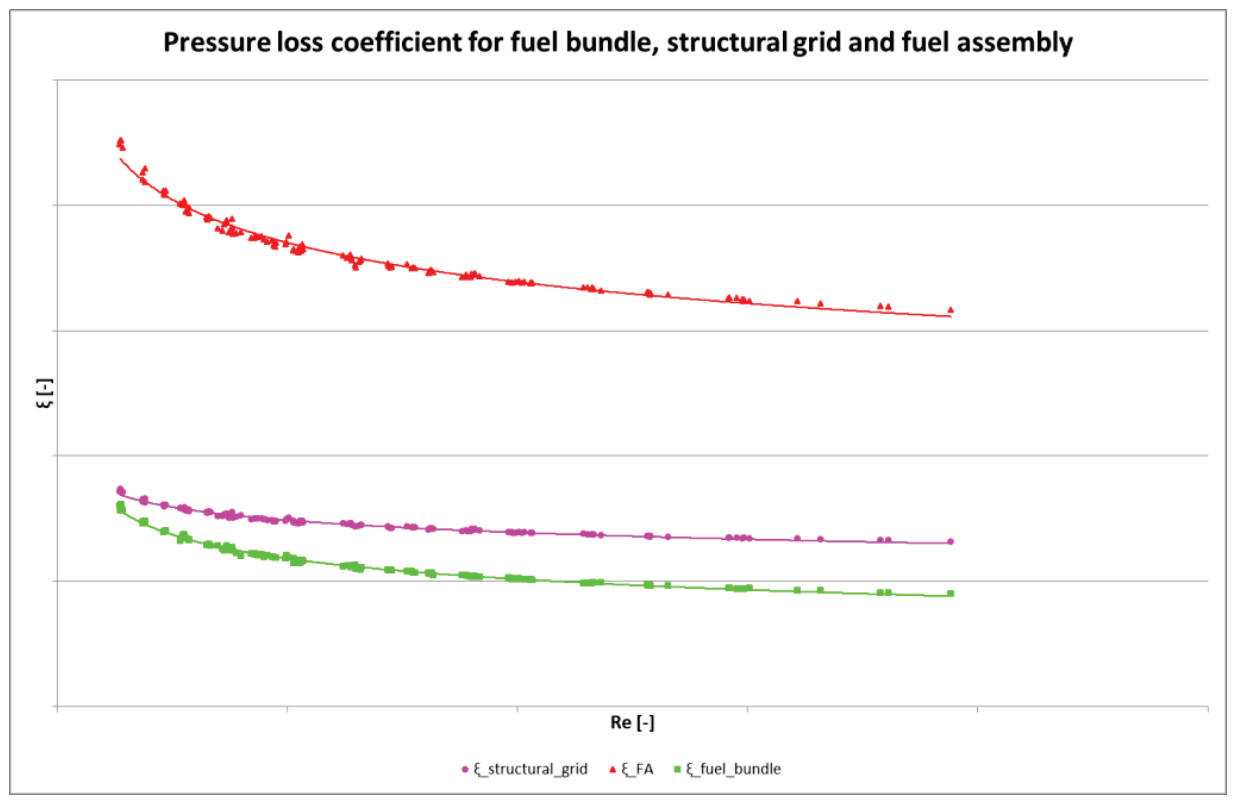

Fig. 4. Result of pressure loss coefficient measurement

\section{Conclusion}

Company Škoda JS built the experimental facility for pressure loss measurement for different types of fuel assemblies VVER. This facility allows performing tests in full range of pressure, temperature and flow rates, the same way like in nuclear reactor in operation. This is important advantage due to other commercial companies, which often measure in low Reynolds numbers region and in the next step extrapolate power curve to operation range of the nuclear reactor.

Experimental channel is made for different types of VVER fuel assemblies, but after some modification it can be used for measurement of western reactor fuel PWR. In present time a part of Large Water Loop is going through modernization for critical heat flux experiments.

Performed measurements of nuclear fuels from different suppliers for nuclear power plant Temelín and Dukovany prove rich experience and personal preparedness. It is supported by measurement of imitators for nuclear power plant Mochovce. The next using of technology can be waited by requirements from the Czech Republic, Poland, Slovakia, Hungary, and so on. 


\section{References}

1. A. Fořtová, R. Škoda, M. Zeman, TEPLATOR - dostupné teplárenství 21. století. All for Power, AF POWER agency a.s. (2020). https://www.ciirc.cvut.cz/cs/teplatordostupne-teplarenstvi-21-stoleti/

2. Nuclear Power, Pressure Drop - Fuel Assembly. https://www.nuclearpower.com/nuclear-power-plant/nuclear-fuel/pressure-drop-fuel-assembly/

3. Shin, ChangHwan \& Chun, Tae-Hyun \& Oh, Dong-Seok \& In, Wang-Kee. (2012). Evaluation of loss coefficient for an end plug with side holes in dual-cooled annular nuclear fuel. Journal of Mechanical Science and Technology. 26. 10.1007/s12206-0120818-4.

https://www.researchgate.net/publication/257775051_Evaluation_of_loss_coefficient f or an end plug with side holes in dual-cooled annular nuclear fuel

4. Nam, Ho \& Kim, Jong-Man \& Seo, Kyung-Won \& Choi, Seok-Ki. (2005).

Development of an Experimental Correlation for a Pressure Loss at a Side Orifice. Journal of Fluids Engineering-transactions of The Asme - J FLUID ENG. 127.

10.1115/1.1881694. https://www.researchgate.net/figure/Effect-of-the-Reynoldsnumber-on-the-pressure-loss-coefficient-of-the-side-orifices-Fig fig5 245356796 